\begin{tabular}{|c|c|c|c|}
\hline \multirow{2}{*}{$\begin{array}{r}\text { Case Reports in } \\
\text { Gastroenterology }\end{array}$} & \multicolumn{2}{|c|}{ Case Rep Gastroenterol 2017;11:511-515 } & \multirow[b]{2}{*}{$\begin{array}{l}\text { Karger } \\
\text { Opengaccess }\end{array}$} \\
\hline & $\begin{array}{l}\text { DOI: } 10.1159 / 000480070 \\
\text { Publisned online: September 6, } 2017\end{array}$ & $\begin{array}{l}\text { (c) } 2017 \text { The Author(s) } \\
\text { Published by S. Karger AG, Basel } \\
\text { www.karger.com/crg }\end{array}$ & \\
\hline & $\begin{array}{l}\text { This article is licensed under the } \\
\text { International License (CC BY-NC) } \\
\text { Usage and distribution for commercia }\end{array}$ & $\begin{array}{l}\text { mons Attribution-NonCommercial } 4 .( \\
\text { ger.com/Services/OpenAccessLicense) } \\
\text { guires written permission. }\end{array}$ & \\
\hline
\end{tabular}

\title{
Malignant Gastric Outlet Obstruction from Pancreatic Cancer
}

\author{
Clare McGrath $^{a}$ Adrian Tsang $^{b}$ Harrish Nithianandan ${ }^{b}$ Eric Nguyen ${ }^{b}$ \\ Patrick Bauer ${ }^{c} \quad$ Kristopher Dennis ${ }^{c}$ \\ ${ }^{a}$ Faculty of Science, Biomedical Science, University of Ottawa, Ottawa, ON, Canada; \\ ${ }^{b}$ Faculty of Medicine, University of Ottawa, Ottawa, ON, Canada; ${ }^{C}$ Division of Radiation \\ Oncology, The Ottawa Hospital, University of Ottawa, Ottawa, ON, Canada
}

\section{Keywords}

Duodenum · Gastric outlet obstruction · Obstruction · Pancreatic cancer $\cdot$ Stomach

\begin{abstract}
Patients with advanced-stage pancreatic cancer are typically burdened by many symptoms that impair functioning and worsen quality of life. We report an exceptional case of a 73year-old woman with T4N1M0 adenocarcinoma of the uncinate process of the pancreas who developed significant gastric outlet obstruction - an uncommon yet potentially lifethreatening complication of disease progression. She developed progressive abdominal pain and emesis, and profound dilatation of her stomach was detected on a radiation therapy simulation CT scan that required urgent decompression. Malignant gastric outlet obstruction must be included in the differential diagnosis when patients with known advanced disease of the pancreas present with obstructive upper gastrointestinal symptoms.
\end{abstract}

(C) 2017 The Author(s)

Published by S. Karger AG, Basel

\section{Introduction}

Gastric outlet obstruction (GOO) can cause significant morbidity including severe weight loss, malnutrition, dehydration, and electrolyte abnormalities [1, 2]. GOO can greatly compromise quality of life and can progress to become life-threatening in advanced cases. GOO 
typically develops in patients with pancreatic cancer due to progression of the primary tumor causing extrinsic compression of the duodenum, and less commonly from lymphadenopathy, carcinomatosis, or liver metastases. Pancreatic cancer is the most common cause of malignant GOO in the western world [3]. Around $15-20 \%$ of patients with pancreatic cancer develop some degree of GOO [3]. Nonbilious vomiting and nausea are the cardinal symptoms of advanced obstruction $[1,2]$. The typical goals of palliative treatments in this setting are to establish a means by which patients can maintain their oral food intake, reduce pain, nausea, and vomiting, and improve their quality of life. We report here an exceptional case of malignant GOO that necessitated urgent decompression.

\section{Case Presentation}

A 73-year-old woman presented to her family physician with an unexplained drop in weight from 90 to $65 \mathrm{~kg}$ in the last 5 months, upper abdominal pain and nausea, acholic stools, and jaundice. She had a history of depression, osteoarthritis, dyslipidemia, a previous laparoscopic cholecystectomy 15 years earlier, and a mesenteric venous thrombosis. She declared a smoking history of 23 pack-years, consumed less than 1 alcoholic drink per week, and denied any use of illicit drugs. The patient's family history was significant: her mother had gall bladder cancer and two maternal aunts had liver and lung cancers, respectively.

Two endoscopic retrograde cholangiopancreatographies (ERCPs) were performed which revealed a common bile duct stricture - a "fuzzy" possibly mass-like area in the adjacent pancreas - and a common bile duct stent was placed to relieve the obstruction. The stomach appeared unremarkable on standard and retroflex views. Further imaging determined that the "fuzzy" appearance of the pancreas was likely due to a perforation from the first ERCP and not a mass.

Three months later, following an episode of cholangitis, she underwent a choledochojejunostomy that revealed an unresectable pancreatic mass extensively infiltrating the root of the small bowel mesentery. A biopsy of the mesentery extension of the mass confirmed a well-differentiated adenocarcinoma. Imaging confirmed her disease as T4N1M0 adenocarcinoma of the uncinate process of the pancreas. Worsening symptoms suggestive of GOO led to another ERCP; it revealed no significant evidence of duodenal obstruction up to the fourth section of the duodenum so a duodenal stent was not placed.

As a result of her advanced disease the patient was referred for consideration of palliative radiotherapy to relieve her gastrointestinal symptoms. At that time she had lost an additional $6 \mathrm{~kg}$ in the past month, and was admitted to hospital with an Eastern Cooperative Oncology Group (ECOG) performance status of 3. She took regular venlafaxine, risperidone, ramipril, rosuvastatin, furosemide, potassium chloride, and dalteparin, and had recently been prescribed senna glycoside, lactulose, docusate, hydromorphone, dexamethasone, and metoclopramide. She complained of aching pain across her epigastrium and upper abdominal quadrants, anorexia, and fatigue. While following a predominantly liquid-only diet, she was suffering from new bouts of projectile vomiting, nausea, and distention. In a 3-week period, her symptoms had worsened to the point where she could barely tolerate oral solids or liquids. On examination she was obese and tender over the epigastrium but devoid of distinct palpable masses. Her abdomen was somewhat tympanic but body habitus obscured more detailed findings.

She underwent a CT scan for radiation planning which surprisingly revealed profound dilatation of the stomach and proximal duodenum (Fig. 1,2) with extrinsic compression and 
likely invasion of the duodenum by the uncinate mass. She was diagnosed with malignant GOO, and several liters of fluid were urgently removed via nasogastric tube suction. In retrospect, it was thought that the obstruction had progressed from transient to complete since the time of her last endoscopy 13 days previously that had ruled out obstruction. Radiation therapy was cancelled and a gastrojejunostomy was performed to bypass the obstruction and relieve her symptoms.

A week later, her symptoms had resolved and she was able to consume solid foods. She was discharged home and began palliative gemcitabine. Unfortunately, the patient later became too weak to complete her third cycle, and 4 months following the diagnosis of GOO she passed away in a hospice.

\section{Discussion}

GOO typically presents with nausea and nonbilious vomiting, but signs of anorexia, malnutrition, dehydration, and epigastric fullness may present earlier. When patients with pancreatic cancer complain of these symptoms it is important to rule out early obstruction and to stay vigilant for changes in symptoms; our patient's case demonstrates how rapidly disease can progress in a short time. Both the proximal and distal duodenum are vulnerable to external compression from masses in the pancreatic head and uncinate process due to their close proximity and long adjacent course.

Initial steps in GOO management include adequate control of pain, decompression with a nasogastric tube, and then consideration of the most effective method to restore adequate nutritional transit, typically via stent placement or surgical diversion [4]. Patients presenting with malignant GOO are often faced with a poor prognosis and limited life expectancy. It is important to determine whether surgical intervention is warranted by considering the patient's overall burden of disease, prognosis, and personal wishes.

In cases of advanced pancreatic disease, radiation therapy is considered a treatment option for malignant obstruction. However, radiation therapy often takes weeks to relieve symptoms of GOO, if effective. More immediate measures, such as stenting or fluoroscopic/endoscopic placement of a feeding tube through the stricture, are rapid, easily accessible, and can provide nourishment in the short term while waiting for a response from radiation therapy. In more advanced cases, surgical diversion is an option, but this is typically only offered when there is a reasonable expectation of the patient receiving life-prolonging therapy in the near future.

Developing an optimal care plan for GOO from pancreatic cancer necessitates a multidisciplinary approach to palliation with input from gastroenterologists, surgeons, radiation and medical oncologists, and palliative care physicians. This extraordinary case demonstrates the importance of considering GOO in the differential diagnosis of upper gastrointestinal symptoms in this patient population. Optimal symptom relief and treatment requires the input of a broad multidisciplinary team. Radiation therapy is an option for treatment but does not relieve symptoms quickly; optimization of endoscopic and surgical options should be considered first to quickly re-establish adequate nutritional intake.

\section{Statement of Ethics}

Approval from an ethics committee is not required for case reports at our institution. 


\section{Case Reports in Gastroenterology}

\begin{tabular}{l|l}
\hline Case Rep Gastroenterol 2017;11:511-515 \\
\hline DOI: 10.1159/000480070 & $\begin{array}{l}\text { ○ 2017 The Author(s). Published by S. Karger AG, Basel } \\
\text { www.karger.com/crg }\end{array}$ \\
\hline
\end{tabular}

McGrath et al.: Malignant Gastric Outlet Obstruction from Pancreatic Cancer

\section{Disclosure Statement}

The authors have no conflicts of interest to disclose.

\section{References}

1 Jeurnink S, van Eijck C, Steyerberg E, Kuipers E, Siersema P: Stent versus gastrojejunostomy for the palliation of gastric outlet obstruction: a systematic review. BMC Gastroenterol 2007;7:18.

-2 No JH, Kim SW, Lim C-H, et al: Long-term outcome of palliative therapy for gastric outlet obstruction caused by unresectable gastric cancer in patients with good performance status: endoscopic stenting versus surgery. Gastrointest Endosc 2013;78:55-62.

-3 Singh SM, Longmire WP Jr, Reber HA: Surgical palliation for pancreatic cancer. The UCLA experience. Ann Surg 1990;212:132-139.

4 Baron TH, Schöfl R, Puespoek A, Sakai Y: Expandable metal stent placement for gastric outlet obstruction. Endoscopy 2001;33:623-628.

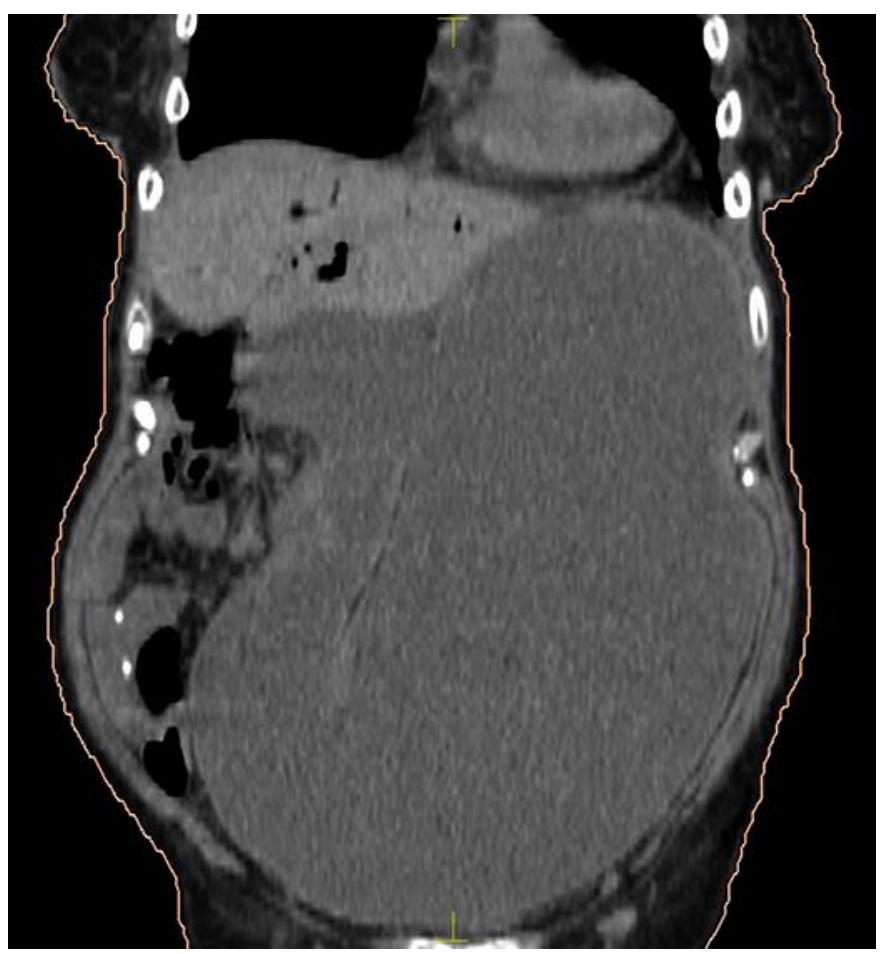

Fig. 1. A coronal plane CT image showing profound dilation of the stomach spanning the abdominal cavity. 


\section{Case Reports in Gastroenterology

\begin{tabular}{l|l}
\hline Case Rep Gastroenterol 2017;11:511-515 \\
\hline DOI: 10.1159/000480070 & $\begin{array}{l}\text { @ } 2017 \text { The Author(s). Published by S. Karger AG, Basel } \\
\text { www.karger.com/crg }\end{array}$ \\
\hline
\end{tabular} \\ McGrath et al.: Malignant Gastric Outlet Obstruction from Pancreatic Cancer}

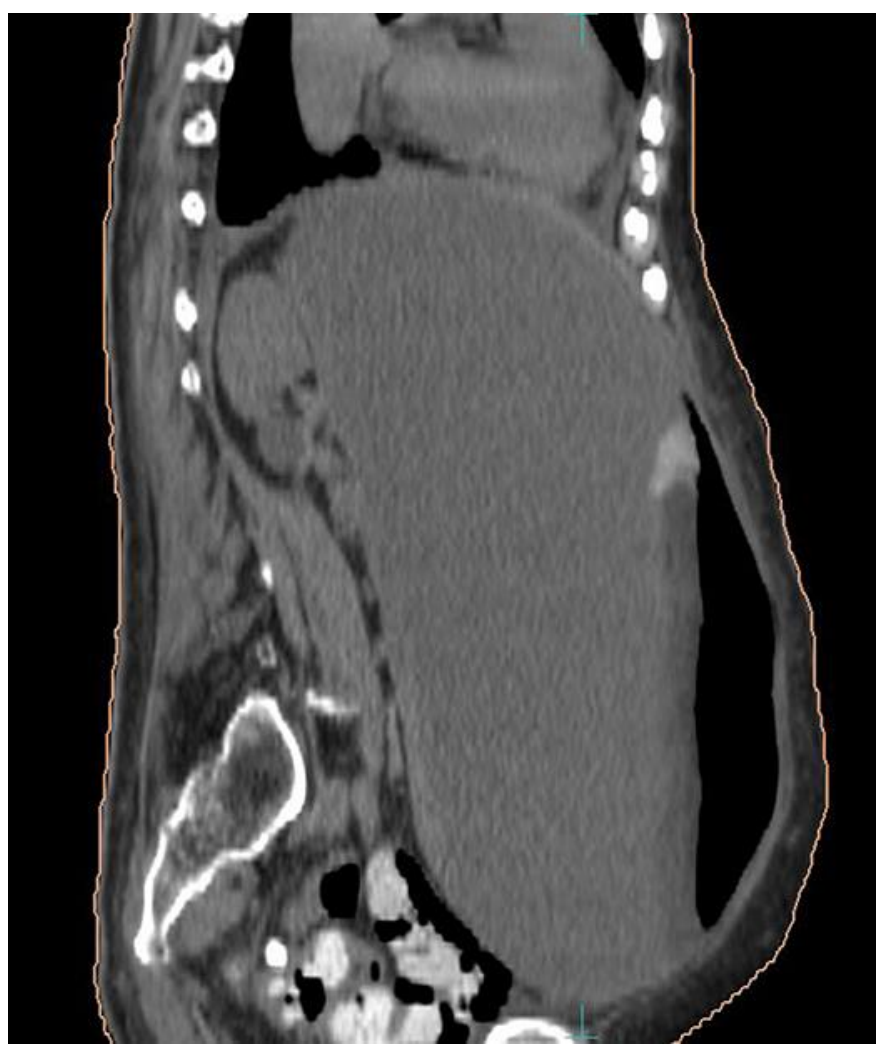

Fig. 2. A sagittal plane CT image showing profound dilatation of the stomach spanning the abdominal cavity. 